\title{
Cutaneous Melanoma pN3 TNM Finding v6 and v7
}

National Cancer Institute

\section{Source}

National Cancer Institute. Cutaneous Melanoma pN3 TNM Finding v6 and v7. NCI

Thesaurus. Code C48863.

Cutaneous melanoma involving four or more regional lymph nodes, or with a finding of matted metastatic nodes, or with in-transit metastasis or satellite(s) with metastasis in regional lymph node(s). (from AJCC 6th and 7th Eds.) 